\title{
Research on Index System Construction of High-standard Basic Farmland
}

\author{
Fengkui Qian ${ }^{1, \text { a, }}{ }^{*}$, Weiwen Wang ${ }^{1}$, Jingye Zhang ${ }^{1}$, Xuefeng Zhang ${ }^{1}$ \\ ${ }^{1}$ College of land and environment, Shenyang Agricultural University, Shenyang, China \\ afkqian@163.com
}

${ }^{*}$ Corresponding author: Fengkui Qian

\begin{abstract}
Keywords: Index System Construction; High-standard; Basic Farmland.
\end{abstract}
\begin{abstract}
Arable land is the most crucially procreative material in human production and living.It not only provides important necessities for human being, but also can protect the ecological environment, ensure the safety of food, maintain social stability and bring economic, social and ecological benefit.With the rapid development of urbanization, the quantity continues to reduce and quality gradually decline of arable land.Although the state formulated a series of measures to protect arable land including launching overall land use planning, demarcating prime farmland protection area, implementing total arable land dynamic equilibrium and carrying out land use control, the overall equality of arable land is still a significant downward trend.Protect arable land play an important role in safeguarding food security and maintaining social stability.Therefore, the construction of high-standard basic farmland is the focus in the study of arable land protection.
\end{abstract}

\section{Research Background}

As a country of large population, food security is major issue relating to national economic development, social stability and national strength.Along with the continuous growth of living standard and constant changes of consumption structure, the demand of food presents the rigid growth with the rapid advance of urbanization and industrialization[1]. For a long time, countries attach great important to the construction of primary farmland and adopted some measures as the basis of grain production including increasing financial input, improving field supporting facility, enhancing the quality of the arable land by land consolidation, strengthening the material basis of agricultural production, building water conservancy projects, soil amelioration and so on.In the first document, for ensuring food security, our country not only need to demarcate the the 1.8-billion mu arable land red line, but also accelerate the construction of high-standard basic farmland with concentrated contiguous, facilities, high and stable yield, stronger disaster resistance and adapted to modern agricultural production and the model of operation[2].Our country constructed high-standard basic farmland by the policy driven and funding.But the construction of high-standard basic farmland is a complicated systems engineering, refer to a lot of engineering composed of land leveling, irrigation and water conservancy, soil amelioration, road project, farmland projecting project, soil improvement project and ecological project and others.And the construction contents of high-standard basic farmland has obvious regional differences.Therefore, it is especially important how to construct high-standard basic farmland suited to local regions. These have become the important and difficult, what kind of standard is the high-standard basic farmland and how to construct high-standard basic farmland, in the course of the construction of high-standard basic farmland.

\section{Research purpose and meaning}

The scope and overage of current construction of high-standard basic farmland is wide.its regional characteristics, natural and social conditions is different.So that construction of high-standard basic farmland is more scientific and reasonable, relevant to the local actual conditions and quite operable., it is necessary that build a reasonable evaluation system in the process of the construction of the 
high-standard basic farmland and adopt different project and measures for different construction patterns[3].This paper, aiming at construction method and model, based on the analysis on the factors influencing the construction of high-standard basic farmland, constructs the evaluation system of the high-standard basic farmland by choosing reasonable indicators. The study area are evaluated through the evaluation system and work out the appropriate grade of the construction of high-standard basic farmland in a region.Donggang as subject, this paper verify the evaluation system and hope to provide theoretical basis and practical reference for layout of the construction of the high-standard basic farmland of the county.

\section{Research method}

The rationality of research method directly affect the scientific and rationality of the results.This paper choose the analytic hierarchy process(AHP), literature study method and Delphi method.AHP can be eliminated to the subjectivity of weighted value.Combining with three methods makes research more scientific and reasonable[4].

Analytic Hierarchy Process.

AHP is a weighted decision method application of the theory of network system and multi-objective comprehensive evaluation method, put forward by Suttie, who is a professor at the university, when he research "According to the size of the industry' s contribution to the national welfare for electric power distribution” for the United States department in the early 1970s.AHP can provides easy decision method for complicated decision-making problems with multiple targets, multiple criteria or no structural characteristics, based on analyzing the essence, influence factors and internal relations of complicated decision-making problems.It is especially suitable for the occasions that the result of the decision is difficult to accurate measurement[5].

Literature study method.

This paper use Literature study method to sums up systematically information related with the agricultural area of soil and put forward general index of the construction of the high-standard basic farmland, under the guidance of land evaluation theory, location theory, regional differentiation theory and so on. This paper also put forward the construction standards of high-standard basic farmland in different region type divided by natural endowments, social economy and ecological protection.

Delphi method.

Delphi method is obtained in forecast conclusion lined with market future trend according concentration prediction area based on prediction opinion of expert team and several rounds of consultation On the basis of the system program, this method adopt anonymous way-between team members can not discuss with each other and not horizontal linkages, and collect all options by repeatedly fill questionnaire.

\section{Index System construction of High-standard basic farmland}

According to status and existing problems of arable land of donggang, there are main problems including unbalanced distribution, poor natural conditions, high proportion of slop cropland, low level of arable land use and so on.The construction of high-standard basic farmland is mainly to transform the existing arable by land leveling, improving irrigation and drainage facilities, soil improvement, farmland shelter forest and ecological protection projects to construct a relatively concentrated contiguous, high and stable yield, good ecology, continuous harvest, water-saving and efficient arable.

Index selection principle.

The main goal of the construction of the well-facilitated primary is realize the transform form low to high quality, and reflect the important thought of arable land protection.

(1)dominant principle 
The suitability evaluation of the construction of the high-standard basic farmland need to select leading factors in numbers influence factors according to the evaluation target and quantify index factor.

(2)Comprehensive analysis principle

On the choice of evaluation index, it should be comprehensive and system and is the comprehensive analysis of the influence of various factors including natural, economic, ecological and so on.

(3)region difference principle

Due to the different of natural and economic condition, It is should be consider that natural and economic attribute in different areas when the index was selected

(4)operation principles

Selected indicators not only to be able to fully reflect the differences of arable land quality of different grades, but also has the strong availability.Correlation between different indexes each other is not big.

Index selection.

(1)Land leveling

To meet the needs of the farm and irrigation, and field construction and soil conservation measures under certain fertility condition, this paper select field regularity and continuous degree to reflect the land leveling within the study area.

(2)Soil improvement

Soil improvement is engineering, mechanical, chemical and biological measures in order to improve the soil physical and chemical properties, soil fertility and nutrient balance and eliminate the soil obstacle factors affecting crop growth.This paper select content of organic matter, effective soil thickness, soil $\mathrm{PH}$, topographic slope, the exposed degree of surface rocks and soil texture to reflect the soil and fertility level within the study area.

(3)Irrigation and drainage

Irrigation and drainage project is various measures for preventing farmland stains and salinity, drought and other disasters, including water resources projects, water conveyance project, spray of micro-irrigation project, drainage project and so on.This paper select ditch density and irrigation guarantee rate to reflect the irrigation and drainage level within the study area.

(4)Field road

Field road project is various measures to meet needs of agricultural material transportation, farming and other agricultural production activities.This paper select density of road network to reflect the field road level within the study area.

(5)Farmland projecting and ecological preservation

Farmland projecting and ecological preservation project is various measures to ensure the safely of land use, maintain and improve the ecological condition, prevent or reduce pollution and natural disasters and so on.This paper select density of forest network and distance from points of geology disaster to reflect farmland projecting and ecological preservation level within the study area.

Index quantifying.

According to the impact analysis of the construction of the high-standard basic farmland, on the basis of the construction principle of zoning index, this paper determines evaluation index of the construction of the high-standard basic farmland.

In this paper, the index system is divided into the target layer, criterion layer and index layer according to the characteristic of the influencing factors. The target layer is hypothesis evaluation system of high-standard basic farmland.Criterion layer is divided into land leveling, soil improvement, irrigation and drainage, field road, farmland projecting , ecological preservation and so on.Index layer includes 13 indicators that are content of organic matter, effective soil thickness, soil $\mathrm{PH}$, topographic slope, the exposed degree of surface rocks, density of road network, regularity, soil texture, continuous degree, ditch density, distance from points of geology disaster, density of forest network and irrigation guarantee rate.Shown in the following table. 


\section{Acknowledgement}

This research was financially supported by the National Natural Science Foundation of China (Grant NO. 41671329) and Natural Science Foundation of Liaoning Province of China (Grant NO. 201602664) and Liaoning Social Science Planning Fund (Grant NO. L15BGL039) and Liaoning Talents Support Program of Higher Education (Grant NO. LJQ2015102)

\section{References}

[1] QIAN F K, WANG Q B. Planning method of the prime farmland based on farmland classification and LESA method. Research of Soil and Water Conservation, 2011, 18(2):251-255.

[2] FANG Q X, YAN F, WEI C F, et al. On Conditions and Capacity of High Standard Basic Farmland Construction in Hilly Area- - Taking Rongchang County of Chongqing as a case. Journal of Southwest China Normal University (Natural Science Edition), 2014, 39(3):122-130.

[3] XUE J, HAN J, ZHANG F R, et al. Development of evaluation model and determination of its construction sequence for well-facilitied capital farmland. Transactions of the Chinese Society of Agricultural Engineering, 2014, 30(5):193-203.

[4] FENG R, WU K N, WANG Q. Time sequence and mode partition of high-standard prime farmland construction in Zhongjiang county, Sichuan province. Transactions of the Chinese Society of Agricultural Engineering, 2012, 28(22):243-251.

[5 ] GUO B B, JIN X B, YANG X H, et al. Study on Zoning Approach for Well-facilitied Capital Farmland: Based on a Comprehensive Assessment of Agricultural Natural Disaster Risk. Journal of Natural Resources, 2014.29(3):377-386. 